\title{
RESEARCH
}

Open Access

\section{The impact of regional astrocyte interferon- y signaling during chronic autoimmunity: a novel role for the immunoproteasome}

\author{
Brandon C. Smith ${ }^{1,2}$, Maksim Sinyuk', Julius E. Jenkins III', Morgan W. Psenicka ${ }^{1}$ and Jessica L. Williams ${ }^{1,3^{*}}$ (D)
}

\begin{abstract}
Background: In early autoimmune neuroinflammation, interferon (IFN) $y$ and its upregulation of the immunoproteasome (iP) is pathologic. However, during chronic multiple sclerosis (MS), IFNy has protective properties. Although dysregulation of the iP has been implicated in neurodegeneration, its function remains to be fully elucidated. Here, we demonstrate that IFNy signaling in regional astrocytes induces the iP and promotes protection of the CNS during chronic autoimmunity.
\end{abstract}

Methods: In a multiple sclerosis (MS) brain, we evaluated mRNA expression and labeled postmortem MS brainstem and spinal cord for iP subunits and indicators of oxidative stress. Primary regional human astrocytes were analyzed for iP regulation and function by quantitative reverse transcription-polymerase chain reaction (qRT-PCR), Western blot, OxyBlot, and reactive oxygen species and caspase activity detection assays. Following immunization with myelin oligodendrocyte glycoprotein (MOG) ${ }_{35-55}$, the role of IFNy signaling and the iP during chronic experimental autoimmune encephalomyelitis (EAE) were assessed using pharmacologic inhibition of the iP and genetic interruption of IFNy signaling specifically in astrocytes. Central nervous system (CNS) tissues were analyzed by immunohistochemistry (IHC) and immunofluorescence, and cell-specific colocalization was quantified.

Results: In MS tissue, iP expression was enhanced in the spinal cord compared to brainstem lesions, which correlated with a decrease in oxidative stress. In vitro, IFNy stimulation enhanced iP expression, reduced reactive oxygen species burden, and decreased oxidatively damaged and poly-ubiquitinated protein accumulation preferentially in human spinal cord astrocytes, which was abrogated with the use of the iP inhibitor, ONX 0914. During the chronic phase of an MS animal model, EAE, ONX 0914 treatment exacerbated the disease and led to increased oxidative stress and polyubiquitinated protein buildup. Finally, mice with astrocyte-specific loss of the IFNy receptor exhibited worsened chronic EAE associated with reduced iP expression, enhanced lesion size and oxidative stress, and poly-ubiquitinated protein accumulation in astrocytes.

Conclusions: Taken together, our data reveal a protective role for IFNY in chronic neuroinflammation and identify a novel function of the iP in astrocytes during CNS autoimmunity.

Keywords: Astrocyte, Immunoproteasome, Interferon-gamma, Regional heterogeneity, Neuroinflammation, Multiple sclerosis, Experimental autoimmune encephalomyelitis

\footnotetext{
* Correspondence: williaj39@ccf.org

${ }^{1}$ Department of Neurosciences, Lerner Research Institute, Cleveland Clinic,

Cleveland, $\mathrm{OH}, \mathrm{USA}$

${ }^{3}$ Brain Health Research Institute, Kent State University, Kent, OH, USA

Full list of author information is available at the end of the article
}

\section{$\triangle B M C$}

(c) The Author(s). 2020 Open Access This article is licensed under a Creative Commons Attribution 4.0 International License, which permits use, sharing, adaptation, distribution and reproduction in any medium or format, as long as you give appropriate credit to the original author(s) and the source, provide a link to the Creative Commons licence, and indicate if changes were made. The images or other third party material in this article are included in the article's Creative Commons licence, unless indicated otherwise in a credit line to the material. If material is not included in the article's Creative Commons licence and your intended use is not permitted by statutory regulation or exceeds the permitted use, you will need to obtain permission directly from the copyright holder. To view a copy of this licence, visit http://creativecommons.org/licenses/by/4.0/ The Creative Commons Public Domain Dedication waiver (http://creativecommons.org/publicdomain/zero/1.0/) applies to the data made available in this article, unless otherwise stated in a credit line to the data. 


\section{Introduction}

Multiple sclerosis (MS) is the most common chronic inflammatory and neurodegenerative disease of the central nervous system (CNS) [1]. During the pathogenesis of MS, there is immune cell infiltration, demyelination, and reactive gliosis within CNS lesions in multiple regions [2]. Relapsing-remitting MS (RRMS) is a subtype that affects approximately $85 \%$ of patients and is characterized by episodic periods of neurological dysfunction, often associated with inflammation, followed by partial or complete recovery. A significant proportion of these patients go on to develop secondary progressive MS (SPMS), during which they have fewer remissions and increasing atrophy, correlating with progressive disability $[3,4]$. Primary progressive MS (PPMS), a third subtype of MS, affects approximately $15 \%$ of patients and is associated with continuous, progressive loss of neurological function after initial diagnosis, without periods of remission $[5,6]$. Of note, it is thought that the pathology associated with RRMS has a significant inflammatory component, while in SPMS and PPMS, inflammation is relatively limited [6]. Thus, it is not surprising that the 12 immunomodulatory, FDA-approved therapies for RRMS [7] have limited effectiveness in SPMS and PPMS patients [8-10] and in some cases have resulted in patient worsening $[11,12]$. Indeed, neutralizing specific inflammatory cytokines in MS patients resulted in exacerbated neurological deficits [13] without reducing lesion load [14], suggesting a complex and potentially protective role for inflammatory cytokines during chronic MS that is not fully understood.

Astrocytes are the most numerous cell type in the CNS and are found in and around MS lesions. Although they have long been considered bystanders of MS pathology, their role in the initiation and resolution of disease is becoming more appreciated $[15,16]$. During MS and experimental autoimmune encephalomyelitis (EAE), an animal model of MS, astrocytes are known to exhibit regional heterogeneity in gene expression and response to inflammation [17-19]. Indeed, ablation of astrocytes following several types of CNS injury leads to sustained inflammation, impaired repair, and increased neurodegeneration [20-29], suggesting that a diverse astrocytic response is critical in healthy tissue preservation and support, minimizing CNS bystander damage during neuroinflammation. However, during chronic MS, inflammation is largely overlooked as it is thought to have a lesser role, especially in SPMS and PPMS patients. Thus, relatively little is known about how regionally distinct astrocytes respond to chronic inflammation to facilitate damage control and recovery.

The role of the cytokine interferon (IFN) $\gamma$ in MS and EAE has been a paradox for more than 3 decades. Many early studies describe a solely pro-inflammatory and pathologic function in the disease [30, 31]. However, more recent evidence supports additional protective roles, particularly in chronic stages, suggesting IFN $\gamma$ has complex, stage-dependent pleiotropic effects in MS and EAE [32-39]. In EAE, systemic or intraventricular administration of IFN $\gamma$ in mice and marmosets during chronic phases reduced disease severity, demyelination, and mortality [40-42] and significantly delayed relapses in a murine model of chronic-relapsing EAE [43]. These studies were corroborated by eliminating IFN $\gamma$ signaling using genetic deletion of Ifng or Ifngr 1, which resulted in higher susceptibility to EAE, increased incidence, more extensive inflammation, encompassing both the spinal cord and hindbrain, and exacerbated disease compared to wild-type (WT) animals [44-52]. Using a signaling deficient dominant-negative Ifngrl driven by the Gfap promoter, the protective effects of IFN $\gamma$ signaling during chronic EAE was linked to astrocytes [53]. While followup studies indicate these effects may be due to altered cytokine release influencing microglia [54], the astrocytespecific mechanisms of IFN $\gamma$-mediated protection are not defined.

Our study demonstrates that IFN $\gamma$ signaling in astrocytes mediates protection during chronic autoimmune neuroinflammation preferentially in the spinal cord through induction of the immunoproteasome (iP). Given that the role of the iP in the CNS is largely unexplored and may have a neuroprotective function in astrocytes, further understanding of the iP may have therapeutic benefit for chronic MS patients for which treatment options are severely limited. In established MS, the prevalence of spinal cord abnormalities is $75-90 \%[55,56]$. Spinal cord lesions and atrophy are considered primary hallmarks of disability accumulation [57-59], and since lesions in the spinal cord are more likely to result in disabling symptoms compared to those in the brain [60], a spinal cord-specific treatment modality would be particularly beneficial. Our study suggests that the iP is a potential mediator of protection during chronic CNS autoimmunity following astrocyte IFN $\gamma$ signaling, and identification of an endogenous inhibitor of the iP might represent a novel therapeutic target that would benefit chronic MS patients with specific patterns of neuroinflammation. In summary, these findings advance our understanding of the astrocyte adaptive immune response during chronic CNS autoimmunity, identify a regionally distinct protective role for astrocytes, and suggest that defining upstream targets that modulate iP expression would facilitate the identification of new targets for the treatment of SPMS and PPMS patients.

\section{Materials and methods}

Human tissue immunohistochemistry (IHC)

Brainstem and spinal cord tissue from MS patients were collected according to the established rapid autopsy 
protocol approved by the Cleveland Clinic Institutional Review Board [61]. Patient information for microarray data is as previously published [62]. Patient tissue (Table 1) was removed, fixed in $4 \%$ paraformaldehyde, and sectioned for IHC analysis. Demyelinated lesions were identified by immunostaining with proteolipid protein (PLP) as described previously [63, 64] and followed by collection of subsequent sections for immunoproteasome and astrocyte labeling. Antigen retrieval was performed using $10 \mu \mathrm{M}$ citrate buffer and boiling briefly. Sections were blocked with $3 \%$ goat serum and $0.01 \%$ Triton X-100 (Sigma-Aldrich) for $1 \mathrm{~h}$ at room temperature and then exposed to antibodies specific for human LMP7 (ThermoFisher Scientific; MA5-15890) or PRDX6 (Abcam; ab59543) and GFAP (Invitrogen; 13-0300) for 4 days at $4{ }^{\circ} \mathrm{C}$. Sections were then washed with PBS-Tween 20 , and secondary antibodies conjugated to Alexa Fluor 488 or 555 (ThermoFisher Scientific) were applied for $1 \mathrm{~h}$ at room temperature. Sections were then treated with $0.3 \%$ sudan black in $70 \%$ ethanol for 3 min, imaged using the $20 \times$ objective of a confocal microscope LSM 800 (Carl Zeiss), and analyzed using ImageJ (NIH).

\section{Human astrocytes}

Primary adult human brainstem and spinal cord astrocytes were obtained from ScienCell Laboratories and grown according to provided protocols in complete ScienCell Astrocyte Medium. Briefly, primary human astrocytes were isolated from the normal brainstem or spinal cord tissue and at $\mathrm{P0}$ were tested for morphology by phase contrast and relief contrast microscopy and GFAP positivity by immunofluorescence. Cell number, viability ( $\geq 70 \%$ ), and proliferative potential ( $\geq 15 \mathrm{pd}$ ) were also assessed, and negative screening for potential biological contaminants was confirmed prior to cryopreservation and receipt of frozen cells at P1. Purity was determined by quantitative reverse transcriptase-polymerase chain reaction qRT-PCR (Fig. S1).

\section{EAE induction}

Animals of mixed sex were induced for EAE at 8-10 weeks of age. C57Bl/6, Gfap-Cre ${ }^{+}$line 77.6, Tie2-Cre ${ }^{+}$, and Ifngr $1^{\mathrm{f} / \mathrm{fl}}$ mice were obtained commercially from The Jackson Laboratory and housed under specific pathogen-free conditions. Mice were crossed according to standard breeding schemes to generate $I f n g r 1^{\mathrm{fl} / \mathrm{fl}}$, Gfap-Cre ${ }^{+}$, and Ifngr $1^{\mathrm{f} / \mathrm{fl}}$ Tie2-Cre ${ }^{+}$mice, and Ifngr $\mathrm{I}^{\mathrm{fl} / \mathrm{fl}}$ littermate controls were used in all experiments. Mice were immunized s.c. with $100 \mu \mathrm{l}$ of a standard emulsion (Hooke Laboratories) containing complete Freund's adjuvant and $\mathrm{MOG}_{35-55}$ on the upper back and base of the tail. Pertussis toxin (80 ng) (Hooke Laboratories) was injected i.p. on the day of immunization and 2 days later. Mice were monitored daily for clinical signs of disease as follows: 0 , no observable signs; 1 , limp tail; 2 , limp tail and ataxia; 2.5, limp tail and knuckling of at least one limb; 3, paralysis of one limb; 3.5; partial paralysis of one limb and complete paralysis of the other; 4 , complete hindlimb paralysis; 4.5 , moribund; 5 , death.

\section{qRT-PCR analysis}

Total RNA was collected from human brainstem and spinal cord astrocytes (ScienCell) using a RNeasy Kit (QIAGEN) according to manufacturer's instructions. Reverse transcription and SYBR Green qRT-PCR were performed as previously described $[65,66]$ for constitutive and immunoproteasome subunits using established primers [67]. Transcript levels were normalized to copies of GAPDH.

\section{Western blotting}

Protein lysates were collected from regional human astrocytes in radioimmunoprecipitation assay (RIPA) buffer (Sigma-Aldrich) supplemented with a protease and phosphatase-3 inhibitor cocktail (Sigma-Aldrich), then $20 \mu \mathrm{g}$ of protein was resolved on a $4-12 \%$ Tris gel and transferred to a polyvinylidene difluoride (PVDF) membrane using the Trans-Blot Turbo system (Bio-Rad) according to standard protocols. Membranes were incubated overnight at $4{ }^{\circ} \mathrm{C}$ in Tris-buffered saline (TBS), $0.1 \%$ Tween $^{\circ} 20$ (TBST) plus 5\% powdered milk and anti-LMP2 (Abcam; ab184172) or anti-Lys48 (Millipore; 05-1307) and anti- $\beta$-actin (ThermoFisher Scientific; MA5-15739) antibodies, washed with TBST 3 times, and then incubated with Alexa Fluor 488, 647, or HRPconjugated secondary antibodies (ThermoFisher Scientific) for $1 \mathrm{~h}$ at room temperature. Membranes were washed with TBST 3 times and imaged using the ChemiDoc MP imaging system (Bio-Rad).

Table 1 MS patient demographics

\begin{tabular}{llllllll}
\hline Patient number & MS type & Age & Gender & Race & Disease duration (years) & Final EDSS & Postmortem interval (h) \\
\hline 81 & PPMS & 73 & F & White & 28.0 & 7.5 & 6.5 \\
92 & SPMS & 71 & F & White & 34.8 & 8.0 & 7.58 \\
159 & SPMS & 55 & F & White & 40.0 & 7.5 & 8.0 \\
\hline
\end{tabular}


In vitro reactive oxygen species (ROS) and caspase detection assays

Human brainstem and spinal cord astrocytes (ScienCell) were seeded in 96-well plates until 70-80\% confluent and treated with media alone or $10 \mathrm{ng} / \mathrm{ml}$ IFN $\gamma$ with or without ONX 0914 for $48 \mathrm{~h}$. ROS were quantified using the DCFDA Cellular ROS Detection Assay Kit (Abcam), caspase activity was quantified using the Caspase-Glo 3/7 Assay Kit (Promega). Cell viability was detected using the CytoPainter Live Cell Labeling Kit (Abcam) and used to normalize ROS and caspase activity. Plates were read on a Victor 3 Multilabel Counter (Perkin Elmer).

\section{OxyBlot}

Human brainstem and spinal cord astrocytes (ScienCell) were seeded in 6-well plates until $70-80 \%$ confluent and treated with media alone or $10 \mathrm{ng} / \mathrm{ml} \mathrm{IFN \gamma}$ for $48 \mathrm{~h}$. Protein lysate was isolated in RIPA buffer supplemented with a protease and phosphatase- 3 inhibitor cocktail (Sigma-Aldrich). Lysate $(20 \mu \mathrm{g})$ was then subjected to derivatization according to manufacturer's instructions (Millipore) and resolved on a 4-12\% Tris gel and transferred onto a PVDF transfer membrane (Bio-Rad) using the Trans-Blot Turbo system (Bio-Rad) according to standard protocols. Membranes were incubated overnight at $4{ }^{\circ} \mathrm{C}$ in TBST plus 5\% powdered milk and probed with either antiDNP (Millipore; S7150) or anti- $\beta$-actin (ThermoFisher Scientific; MA5-15739) primary antibodies, washed with TBST 3 times, and then incubated with HRP-conjugated secondary antibodies (Millipore) for $1 \mathrm{~h}$ at room temperature. Membranes were washed with TBST 3 times, imaged using the ChemiDoc MP imaging system (Bio-Rad), and analyzed as previously described [68].

\section{Immunoproteasome inhibition}

For in vitro experiments, the selective immunoproteasome inhibitor ONX 0914 (Cayman Chemical) was dissolved in $0.25 \%$ ethanol and used at a working concentration of $50 \mu \mathrm{M}$. For in vivo immunoproteasome inhibition, ONX 0914 was formulated in an aqueous solution of $14 \%$ ethanol in PBS, which was used as a vehicle control, and administered to mice as an i.p. bolus dose of $10 \mathrm{mg} / \mathrm{kg}$ after a stabilization or reduction in EAE clinical score for two consecutive days was observed. Seven days after vehicle or ONX 0914 treatment, mice were perfused and CNS tissue was prepared for IHC analysis.

\section{Murine tissue IHC}

Mice were intracardially perfused with PBS followed by $4 \%$ paraformaldehyde (PFA), and CNS tissue was removed and fixed in $4 \%$ PFA at $4^{\circ} \mathrm{C}$ for $24 \mathrm{~h}$. Tissue was then cryopreserved in $30 \%$ sucrose and frozen in O.C.T. Compound (Fisher HealthCare). Frozen, sequential transverse sections
$(12 \mu \mathrm{m})$ were slide mounted and stored at $-80^{\circ} \mathrm{C}$. Tissue sections were blocked with $10 \%$ goat serum and $0.1 \%$ Triton X-100 (Southern Biotech) for $1 \mathrm{~h}$ at room temperature and then incubated with anti-myelin basic protein (MBP) (Abcam; ab7349), anti-LMP2 (Abcam; ab184172), antiPRDX6 (Abcam; ab59543), anti-Lys48 (Millipore; 051307), anti-GFAP (Invitrogen; 13-0300), anti-IFNGR1 (ThermoFisher Scientific; 13-1191-82), or anti-Iba1 (Wako Chemicals; 019-19741) primary antibodies overnight at $4{ }^{\circ} \mathrm{C}$. Secondary antibodies conjugated to Alexa Fluor 488 or Alexa Fluor 555 (ThermoFisher Scientific) were applied for $1 \mathrm{~h}$ at room temperature. Nuclei were counterstained with DAPI (ThermoFisher Scientific) diluted in PBS. Sections were analyzed using the $20 \times$ objective of a confocal microscope LSM 800 (Carl Zeiss). Images shown are representative of 4-8 images taken across two tissue sections at least $100 \mu \mathrm{m}$ apart per individual mouse. The mean positive area, intensity, and Mander's coefficient of colocalization were determined by setting thresholds using appropriate isotype control antibodies and quantified using ImageJ software (NIH).

\section{Statistics}

EAE data were analyzed using the nonparametric MannWhitney $U$ test. Other data were analyzed with parametric tests (2-tailed Student's $t$ test or 2-way analysis of variance (ANOVA), with correction for multiple comparisons where appropriate. All statistical analyses were performed using GraphPad Prism Version 7 software (GraphPad Software). A $P$ value of less than 0.05 was considered statistically significant.

\section{Results}

The iP is expressed in regional astrocytes within MS lesions and is associated with reduced oxidative stress

In several neurodegenerative diseases, the iP is known to clear ROS and degrade poly-ubiquitinated proteins [69-71], and there is evidence that the iP may be dysregulated during MS and experimental autoimmune encephalomyelitis (EAE), an animal model of MS [71-73]. Additionally, astrocytes have been implicated in modulating neuroinflammation and neurodegeneration [15, 16, 74]; however, the role of the astrocyte iP during MS and EAE has not yet been fully elucidated. To determine the role of the iP in the MS brain, we evaluated the mRNA expression of genes associated with the classical proteasome (PSMB7) and the iP (PSMB8) in previously published MS patient tissue microarray data [62]. Strikingly, we found PSMB7 to be significantly downregulated while PSMB8 was significantly increased in white matter lesions (WML) compared to controls and normal-appearing white matter (NAWM; Fig. 1a, b). Although lesions in the brainstem and spinal cord are common and result in pronounced disability during MS $[75,76]$ and EAE [77], relatively little is known about lesion 

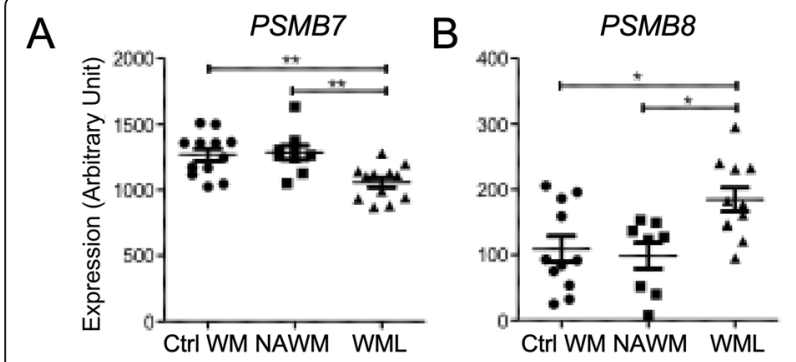

C

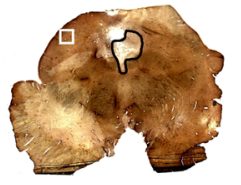

D
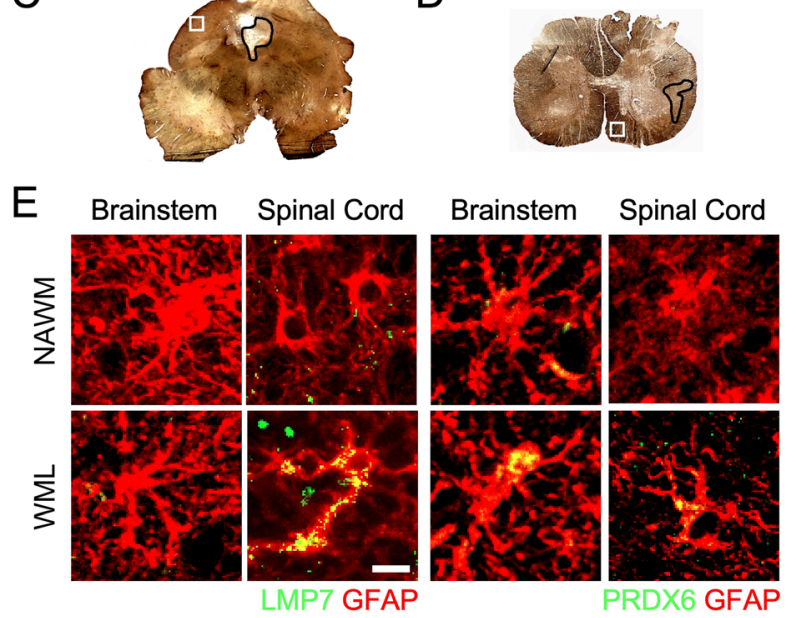

Fig. 1 Regional astrocyte oxidative stress and iP expression in chronic MS WMLs. $\mathbf{a}$ and $\mathbf{b}$ RNA was extracted from the cortical WM of control and MS ( $n=7-12)$ patients and analyzed via microarray and the relative expression of (a) PSMB7 and (b) PSMB8 were assessed as described [62]. $\mathbf{c}$ and $\mathbf{d}$ MS demyelinating lesions (black outline) and NAWM (white square) were identified by PLP labeling of the (c) brainstem and (d) spinal cord in MS patients. e GFAP ${ }^{+}$ astrocytes (red) were co-labeled with either LMP7 or PRDX6 (green) in NAWM or in WML of the brainstem or spinal cord. Scale bar: $10 \mu \mathrm{M}$. ${ }^{*} P<0.05,{ }^{*} P<0.01$. Ctrl WM control white matter, NAWM normal-appearing white matter, WML white matter lesion

pathology in these regions. Thus, we examined NAWM and areas of demyelination in the brainstem (Fig. 1c) and spinal cord (Fig. 1d) of MS patients (Table 1), labeling an iP subunit (LMP7) and an indicator of oxidative stress (PRDX6) within astrocytes by IHC. In WMLs, there was an inverse relationship between LMP7 and PRDX6 specifically in the spinal cord (Fig. 1e), suggesting that the iP may play a role in reducing oxidative stress in MS lesions and that there may be a difference in iP expression and/or function in regional astrocytes.

Regional astrocytes differentially regulate iP expression in response to IFN $\gamma$ and during $E A E$

Astrocytes are regionally heterogeneous in morphology, gene expression, and function during physiological and pathological conditions $[78,79]$. Since the iP is readily induced by IFN $\gamma$, which is present at all stages of MS $[30,34]$, and astrocytes are in and around MS lesions and respond to IFN $\gamma$, we further explored heterogenous regulation of the astrocyte $\mathrm{iP}$ between the brainstem and spinal cord driven by IFN $\gamma$. Using primary human astrocytes from the brainstem and spinal cord (Fig. S1), we analyzed iP transcript levels following IFN $\gamma$ stimulation over the course of $48 \mathrm{~h}$. Expression levels of the iP subunits PSMB8, PSMB9, and PSMB10 increased in spinal cord astrocytes compared to those in brainstem-derived astrocytes, with the most robust transcript upregulation occurring at $48 \mathrm{~h}$ (Fig. 2a). Of note, there was no appreciable change in constitutive proteasome subunit transcript in either region following IFN $\gamma$ stimulation (Fig. $\mathrm{S} 2$ ). We confirmed regional differences in iP expression in astrocytes at the protein level by analyzing protein lysate from human brainstem and spinal cord astrocytes incubated with and without IFNy (Fig. 2b,c). Although IFN $\gamma$ expression is robust and perpetuates acute inflammation in both MS and EAE, it is still present during chronic disease, albeit at lower levels [80, 81]. To determine the regional sensitivity of astrocytes to IFNy stimulation, we measured the transcript expression levels of iP subunits following an IFN $\gamma$ dose titration over 24 or $48 \mathrm{~h}$. Interestingly, compared to those from the brainstem, all of the iP subunits were upregulated specifically in astrocytes from the spinal cord following exposure to low concentrations of IFN $\gamma$ after $48 \mathrm{~h}$ (Fig. 2d). To determine if regional

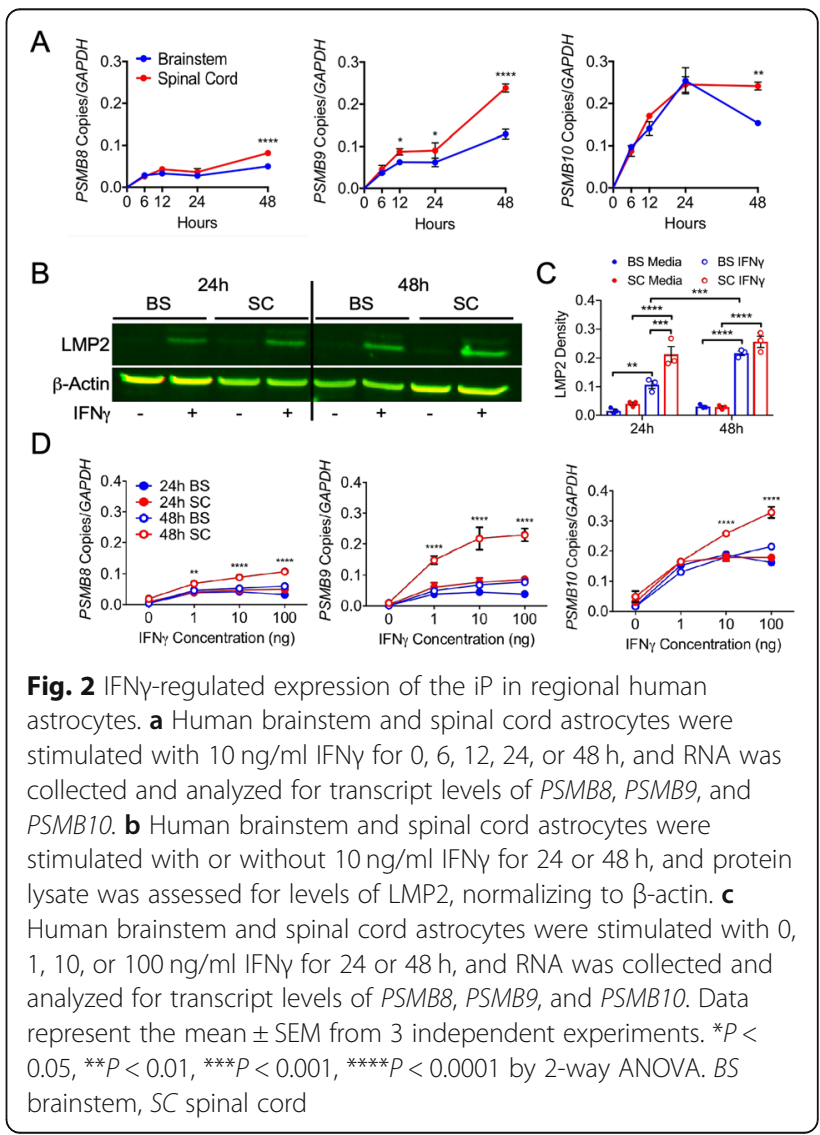


differences in astrocyte iP expression were present in vivo during neuroinflammation, we induced EAE in Ifngr ${ }^{\mathrm{f} / \mathrm{fl}}$ Tie2-Cre ${ }^{+}$mice, in which the IFN $\gamma$ receptor (IFNGR1) is deleted from endothelial cells of the blood-brain barrier $[82,83]$, conferring inflammation in both the brainstem and spinal cord and maintaining genetically WT astrocytes. Signs of both classical EAE, primarily affecting the spinal cord, and atypical EAE, which affects the hindbrain, were monitored (Fig. S3A) [44, 53]. To determine if iP expression is regionally distinct, we first confirmed that lesion size between the brainstem and spinal cord was consistent in Ifngr $1^{\mathrm{fl} / \mathrm{fl}}$ Tie2-Cre ${ }^{+}$mice (Fig. S3B). While the average lesion size was similar between regions in Ifngr $1^{\mathrm{fl} / \mathrm{fl}}$ Tie2-Cre ${ }^{+}$ mice, iP expression in spinal cord astrocytes was significantly increased compared to those in the brainstem (Fig. $\mathrm{S} 3 \mathrm{~B})$. These data demonstrate that both in human astrocytes and in an in vivo model of regional autoimmune neuroinflammation, astrocyte, iP expression is preferentially upregulated by IFN $\gamma$ in spinal cord astrocytes compared to those in the brainstem. This suggests that in the spinal cord, the iP is potentially a primary astrocyte-mediated protection mechanism during neuroinflammation, and that brainstem astrocytes may engage alternate pathways.

\section{ROS and poly-ubiquitinated protein accumulation are abrogated by the astrocyte iP}

The best known function of the iP is its role in antigen processing; however, since astrocytes present little or no antigen [84-86], alternate functions of the iP were examined, namely clearance of ROS and oxidatively damaged and poly-ubiquitinated proteins [87]. To determine the role of the iP in astrocyte viability and ROS clearance, we treated regional human astrocytes with or without IFN $\gamma$ and a specific inhibitor of the iP, ONX 0914 [88-90]. Following iP inhibition, an increase in caspase activity was observed only in spinal cord astrocytes compared to media treatment, which was significantly enhanced compared to those from the brainstem (Fig. 3a). Next, we observed an overall increase in cellular ROS in astrocytes treated with ONX 0914, with enhanced ROS in spinal cord astrocytes compared to brainstem astrocytes. Interestingly, in cells treated only with IFN $\gamma$, astrocytes from the spinal cord produced less ROS than brainstem-derived astrocytes (Fig. 3b). Assessment of oxidative protein damage revealed an increase in spinal cord versus brainstem astrocytes following iP inhibition. There was also a treatment effect in spinal cord astrocytes with a reduction in oxidatively damaged proteins following IFNy treatment (Fig. 3c,d). Assessment of poly-ubiquitinated proteins revealed an increase in both spinal cord and brainstem astrocytes following iP inhibition in the presence of IFN $\gamma$ (Fig. 3e,f). Taken together, these data suggest that IFN $\gamma$-mediated induction of the iP in spinal cord astrocytes reduces ROS and oxidatively damaged and poly-ubiquitinated proteins which may lead to preservation of proper astrocyte function.

\section{Inhibition of the iP exacerbates chronic EAE}

Although iP inhibition during acute EAE resulted in ameliorated disease associated primarily with dampened peripheral immune responses [91], the role of the iP during the relatively less inflammatory chronic phase of EAE has not yet been explored. We induced EAE in WT C57Bl/6 mice, which develop spinal cord-associated inflammation, and two days after peak disease, we administered a single dose of ONX 0914 or vehicle, and the clinical course was monitored. Following treatment, EAE rapidly worsened in mice receiving ONX 0914 compared to vehicle-treated mice (Fig. 4a). Further, IHC labeling revealed an increase in lesion size and a loss of GFAP ${ }^{+}$ astrocyte labeling in ONX 0914-treated mice (Fig. 4b-e). To determine if this corresponded to a reduction in oxidative stress and poly-ubiquitinated protein accumulation, we performed IHC analysis on the tissue 7 days following treatment. Indeed, IHC labeling of PRDX6 indicated enhanced oxidative stress and oxidative stress within $\mathrm{GFAP}^{+}$astrocytes in lesions of ONX 0914-treated compared to vehicle-treated mice (Fig. 4f,g). Similarly, Lys48 labeling revealed an increase in total polyubiquitination and poly-ubiquitination within $\mathrm{GFAP}^{+}$astrocytes in lesions of ONX 0914-treated mice compared to those treated with vehicle (Fig. 4h,i). These data suggest that the iP has a role in reducing oxidative stress and poly-ubiquitinated protein build-up in astrocytes during chronic EAE, which may contribute to reduced lesion size and disease recovery.

\section{IFN $\gamma$-mediated iP upregulation in astrocytes is protective during chronic EAE}

Diminished IFN $\gamma$ signaling in astrocytes is known to exacerbate chronic EAE [53]. We demonstrated that the iP is regulated by IFN $\gamma$-signaling and observed an increase in oxidative stress and poly-ubiquitinated protein accumulation specifically in astrocytes during in vivo iP inhibition. However, of note, administration of ONX 0914 inhibits the iP globally, and since astrocytes can be influenced by other cell types including $\mathrm{T}$ cells and microglia during neuroinflammation [92, 93], we next utilized a more astrocyte-specific approach. To further examine the role of IFN $\gamma$-mediated iP induction in astrocytes during EAE, we immunized mice in which Gfap-expressing astrocytes are deficient in Ifngrl (Fig. S4). Following EAE onset, Ifngr $1^{\mathrm{fl} / \mathrm{fl}} \mathrm{Gfap}$-Cre ${ }^{+}$mice had a milder acute disease compared to littermate controls as previously described [92]. However, chronic disease was significantly exacerbated in Ifngr $1^{\mathrm{fl} / \mathrm{fl}} \mathrm{Gfap}-\mathrm{Cre}^{+}$mice and weight loss was enhanced (Fig. 5a,b). Further, compared to Ifngr $\mathrm{f}^{\mathrm{fl} / \mathrm{fl}}$ controls, Ifngr $1^{\mathrm{fl} / \mathrm{fl}}$ Gfap-Cre ${ }^{+}$mice had increased lesion 

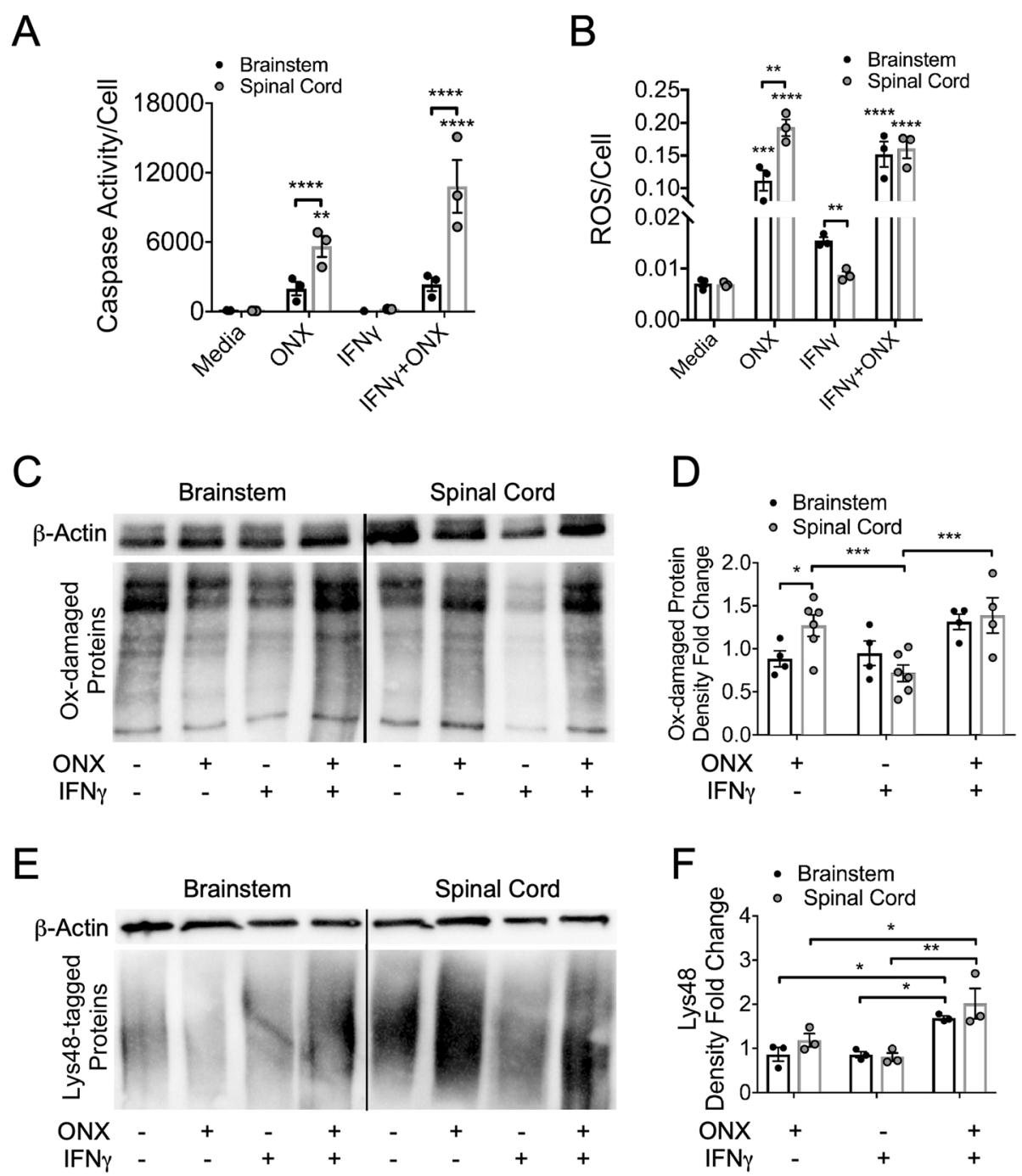

Fig. 3 The effect of iP inhibition on regional astrocyte death, ROS production, oxidatively damaged and poly-ubiquitinated protein load. a-e Human brainstem and spinal cord astrocytes were stimulated with or without $10 \mathrm{ng} / \mathrm{ml}$ IFNy and/or ONX 0914 for $48 \mathrm{~h}$. a Caspase activity and $\mathbf{b}$ ROS were measured and normalized to live cells. c Protein lysate was collected and derivatized, and (d) oxidatively damaged protein accumulation was quantified and normalized to $\beta$-actin levels. e Protein lysate was probed for Lys48-labeled poly-ubiquitinated proteins, normalized to $\beta$-actin expression, and (f) quantified. Data represent the mean \pm SEM from 3 independent experiments. ${ }^{*} P<0.05,{ }^{* *} P<0.01,{ }^{* * *} P<$ $0.001,{ }^{* * *} P<0.0001$ by 2 -way ANOVA. ROS reactive oxygen species, Ox-damaged oxidatively damaged

size and reduced myelin basic protein (MBP) expression by IHC (Fig. 5c,d). To determine if there was a corresponding reduction in astrocyte iP expression and function in Ifngr $\mathrm{I}^{\mathrm{fl} / \mathrm{fl}} \mathrm{Gfap} \mathrm{Cre}^{+}$mice, we performed $\mathrm{IHC}$ analysis during chronic EAE. As expected, there was a decrease in both total iP expression and iP colocalization with $\mathrm{GFAP}^{+}$astrocytes within the lesions of Ifngr $1^{\mathrm{f} / \mathrm{fl}}$ Gfap-Cre $^{+}$compared to Ifngr $1^{\mathrm{fl} / \mathrm{fl}}$ mice (Fig. 5e,f). To confirm if there was an astrocyte-specific downregulation of iP expression, we analyzed LMP2 colocalization with $\mathrm{Iba}^{+}$microglia/monocytes and found no difference between genotypes (Fig. S5). Further IHC labeling revealed an increase in both total PRDX6 and Lys48 and PRDX6 and Lys48 colocalized with GFAP $^{+}$astrocytes within the lesions of Ifngr $1^{\mathrm{fl} / \mathrm{fl}}$ Gfap-Cre ${ }^{+}$compared to Ifngr $1^{\mathrm{fl} / \mathrm{fl}}$ mice (Fig. $5 \mathrm{~g}-\mathrm{j}$ ), suggesting enhanced oxidative stress and poly-ubiquitinated protein accumulation specifically in astrocytes of Ifngr $\mathrm{I}^{\mathrm{fl} / \mathrm{fl}}$ Gfap-Cre ${ }^{+}$mice. These data suggest that during chronic EAE, IFNY signaling in astrocytes enhances iP expression, which leads to a reduction in CNS tissue damage, allowing recovery from clinical disease.

\section{Discussion}

Interferony is primarily pro-inflammatory in acute stages of MS and EAE [81]; however, there is evidence to suggest that in chronic MS and EAE, IFN $\gamma$ has protective functions $[37,38,53]$. In this study, we confirm these findings 


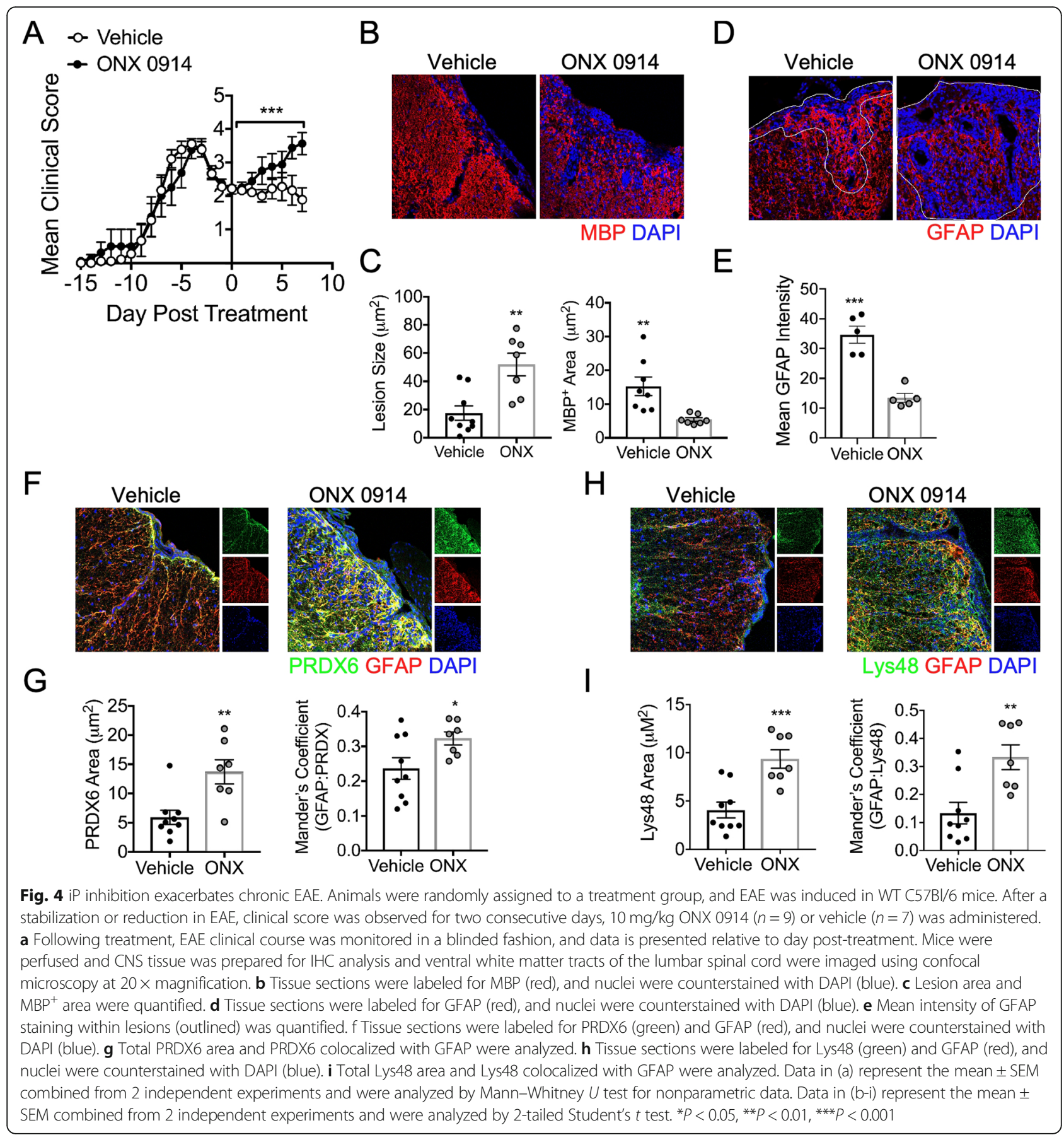

and demonstrate that IFNY signaling in astrocytes leads to the upregulation of the $\mathrm{PP}$, dampening chronic EAE severity. Our studies indicate that IFN $\gamma$-mediated upregulation of the iP leads to preservation of astrocyte integrity by reducing ROS and degrading oxidatively damaged and polyubiquitinated proteins. In vivo, IFN $\gamma \mathrm{R}$ signaling was critical for iP upregulation in astrocytes, which was associated with a reduction in lesion size and disease severity during chronic EAE. Further, studies using postmortem MS tissue, in vitro astrocytes, and models of EAE showed enhanced iP expression in the spinal cord compared to the brainstem, suggesting that spinal cord astrocytes more readily upregulate the iP upon IFNy stimulation, leading to enhanced region-specific protection during CNS autoimmunity. Previous findings suggest that enhanced IFN $\gamma$ responsiveness of spinal cord astrocytes may be due to increased IFNGR1 expression at baseline relative to those from the brainstem [92].

These findings reveal the importance of IFN $\gamma$ signaling and its role in astrocyte iP regulation during chronic 

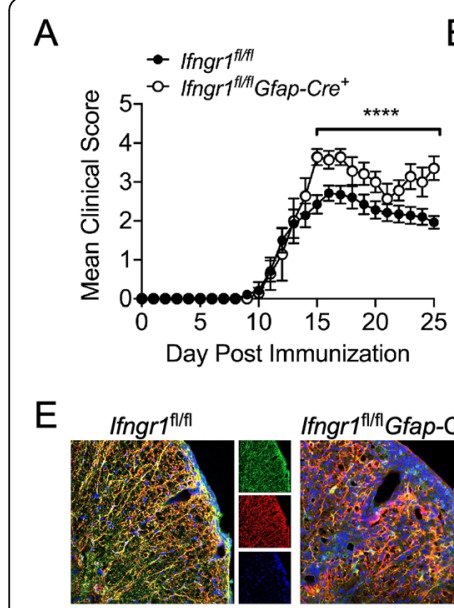

$\mathrm{F}$

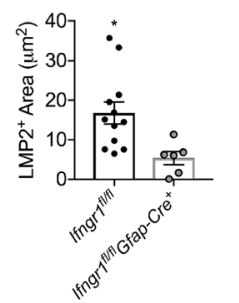

B

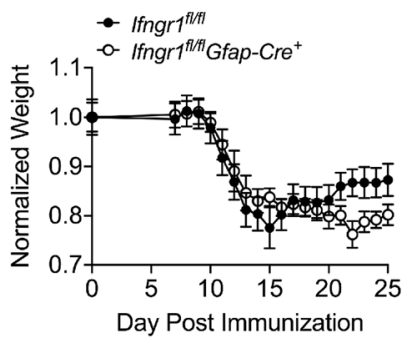

C

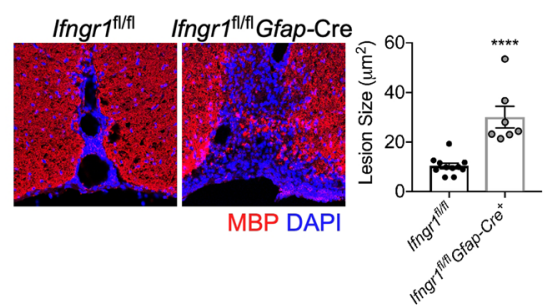

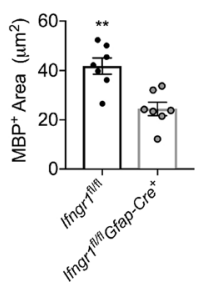

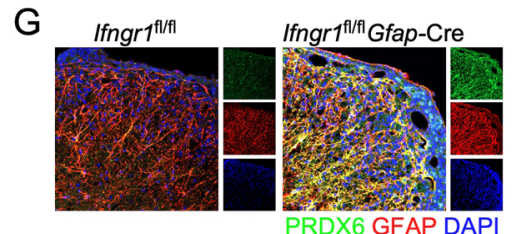

$\mathrm{H}$
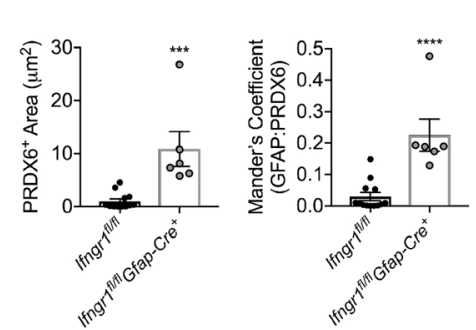
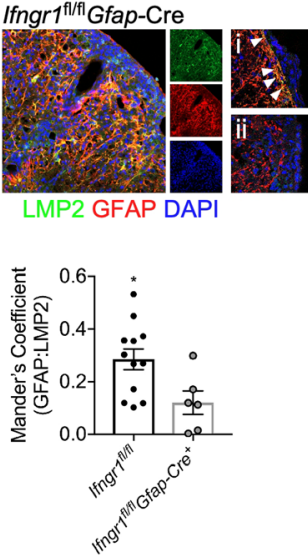

MP2 GFAP DAP

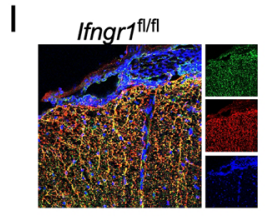

$\mathrm{J}$

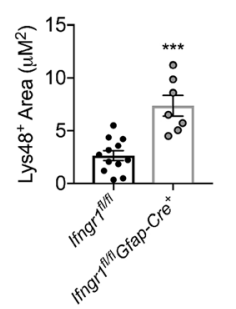

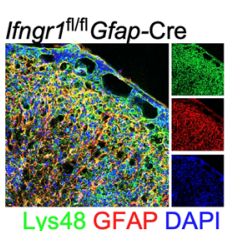

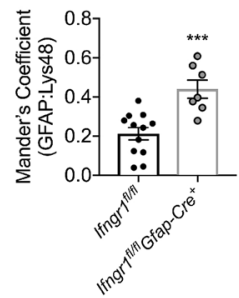

Fig. 5 Astrocyte IFNy signaling upregulates the iP during EAE. EAE was induced in Ifngr $7^{\text {fl/fl }}$ Gfap-Cre ${ }^{+}$mice $(n=7)$ and Ifngr $7^{f / f l} \mid$ littermates $(n=$ 12) and (a) EAE clinical course and (b) weight loss were blindly monitored. Following 25 days post-immunization, mice were perfused, and the CNS was removed and cryopreserved for $\mathrm{HC}$ analysis. Ventral white matter tracts of the lumbar spinal cord were imaged using confocal microscopy at 20 a magnification. c Tissue sections were labeled for MBP (red), and nuclei were counterstained with DAPI (blue). d Lesion area and $\mathrm{MBP}^{+}$area were quantified. e Tissue sections were labeled for LMP2 (green), GFAP (red), and nuclei were counterstained with DAPI (blue).

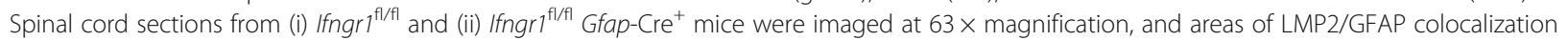
are indicated (white arrows). f Total LMP2 area and LMP2 colocalized with GFAP were analyzed. $\mathbf{g}$ Tissue sections were labeled for PRDX6 (green) and GFAP (red), and nuclei were counterstained with DAPI (blue). $\mathbf{h}$ Total PRDX6 area and PRDX6 colocalized with GFAP were analyzed. $\mathbf{i}$ Tissue sections were labeled for Lys48 (green) and GFAP (red), and nuclei were counterstained with DAPI (blue). j Total Lys48 area and Lys48 colocalized with GFAP were analyzed. Data in (a) represent the mean \pm SEM combined from 2 independent experiments and were analyzed by Mann-

Whitney $U$ test for nonparametric data. Data in $\mathbf{c}-\mathbf{j}$ represent the mean \pm SEM combined from 2 independent experiments and were analyzed by 2-tailed Student's $t$ test. ${ }^{*} P<0.05,{ }^{* *} P<0.01,{ }^{* * *} P<0.001,{ }^{* * *} P<0.0001$

stages of neurodegenerative disease, and they highlight the stage-specific roles of IFNY during MS and EAE. Previous studies have shown that iP inhibition by ONX 0914 during acute disease leads to EAE amelioration by dampening peripheral immune responses [91, 94]. Importantly, it has recently been shown that IFNY diverts OPCs from differentiating into mature oligodendrocytes to cells with antigen presenting capabilities via upregulation of the iP, a critical immune-priming process during acute EAE [95]. However, iP inhibition following the acute phase of EAE, using the same dose of ONX 0914, we found that disease severity was significantly exacerbated. Indeed, IFNYR signaling specifically in astrocytes was beneficial, resulting in smaller lesions, less demyelination, and a reduction in EAE severity in control mice compared to those with dampened IFNYR1 in astrocytes [53]. Here, we extend those findings by demonstrating that upregulation of the iP is a potential mechanism by which IFNY signaling protects the CNS during chronic neuroinflammation. We demonstrate that the iP is expressed in astrocytes during chronic MS and that administration of a specific iP inhibitor during chronic EAE exacerbates clinical disease, likely as a result of inhibiting the alternate functions of the iP including clearance of ROS and poly-ubiquitinated proteins.

While IFN $\gamma$ signaling is known to directly induce iP expression [96], other factors including aging, stress, and ROS also contribute to iP upregulation [97-99]. Due to normal metabolic processes and oxidative and age-related stress, there is a basal level of iP expression that supports cellular homeostasis [97]. Without a functioning iP, damaged proteins can rapidly accumulate under oxidative stress conditions, like EAE and MS, to an extent that exceeds the proteolytic capacity of the constitutive proteasome, which leads to the formation of harmful protein aggregates and cell apoptosis [68, 100, 101]. Importantly, oxidative and inflammatory genes are modified during EAE and primarily in astrocytes in MS lesions [101-105]. Gene modifications in astrocytes during inflammatory 


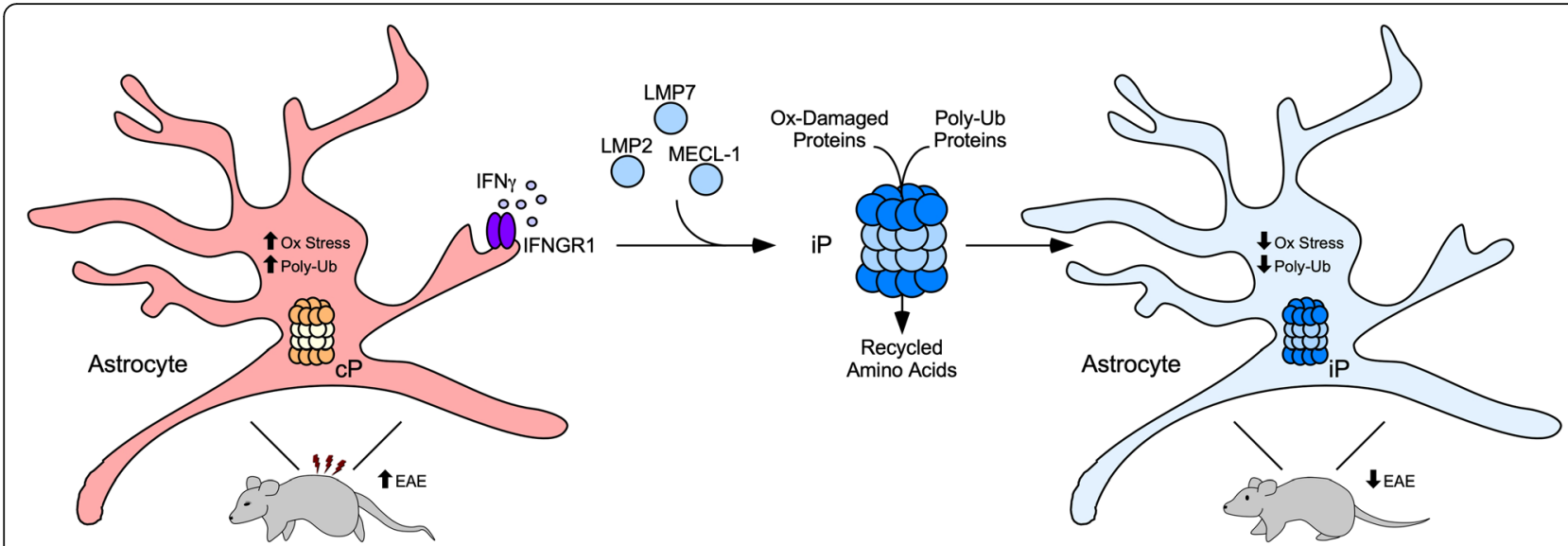

Fig. 6 Schematic representation of the proposed IFNy-iP axis active in astrocytes during chronic EAE. During MS and EAE, oxidative stress occurs in astrocytes leading to rapid accumulation of oxidatively damaged proteins, which are tagged for degradation by the iP via poly-ubiquitin chains. IFNGR1 signaling in astrocytes leads to the conversion of the constitutive proteasome (cP) to the iP, which more efficiently reduces oxidative stress and removes poly-ubiquitinated proteins, leading to a reduction in lesion size and improved EAE clinical score

processes include those that would support an increase in ubiquitinated protein degradation, including increases in ubiquitin ligases necessary for proteasome recognition [106, 107]. Consistent with this, oxidized and polyubiquitinated proteins accumulated in chronic MS white matter with reduced iP peptidase activity [108] and in the brains of mice lacking the iP subunits LMP2 and LMP7 [68, 109]. Further, LMP7-deficient mice had more severe CNS oxidative damage and exacerbated EAE [68]. While the pathological consequences of impaired iP activity in chronic MS and EAE are unknown, the impact of accumulated, damaged protein aggregates and reduced degradation of various signaling and pro-apoptotic molecules likely contribute to neurodegeneration.

These findings broaden our understanding of astrocyte heterogeneity in the CNS. Although regional heterogeneity of astrocytes in neurophysiologic functions $[18,19,66]$ and in many disease models $[110,111]$, including $\operatorname{EAE}[79,112$, 113], has been appreciated, there are no studies to date that have described a regional role for the iP in the CNS. However, a regional difference in Type I IFN signaling in astrocytes has been described [66]. Here, we expand on those findings, demonstrating a regional increase in iP expression preferentially in spinal cord astrocytes compared to those from the brainstem in response to IFN $\gamma$. We show that this increase in iP expression in spinal cord astrocytes is protective, as inhibition of the iP results in reduced astrocyte viability, increased ROS production, and accumulation of damaged proteins. This diverse astrocytic response is critical in healthy tissue preservation and support as it minimizes prolonged CNS exposure to cytotoxic inflammation. Indeed, ablation of astrocytes following several types of CNS injury leads to sustained inflammation, impaired blood-brain barrier repair, and increased neurodegeneration [20-29]. Additionally,
IFNGR1 signaling induces several cellular pathways during neuroinflammation. Notably, IFNGR1 activation in astrocytes results in the secretion of interleukin (IL)-27, which regulates effector $\mathrm{T}$ cell functions during EAE via IL-10 induction [53]. Thus, the survival of astrocytes following damage is key in CNS recovery. Taken together, our data suggest that the astrocyte iP may be a key mechanism of protection in the spinal cord while other distinct CNS regions may rely on alternate pathways to facilitate damage control and recovery during chronic neurodegeneration and CNS inflammation.

Our study demonstrating a role for the astrocyte iP in promoting protection during chronic neuroinflammation has definite clinical implications. It has been proposed that inhibition of the iP can serve as an effective therapeutic modality for MS; however, given the data presented here, consideration of disease stage is of utmost importance [73, 114]. In progressive MS patients, improving symptoms correlated with high levels of serum IFN $\gamma$, while patients with clinical worsening had relatively low levels of serum IFNy [37], suggesting IFN $\gamma$-induced iP expression may have a role in MS stabilization or even recovery. Since the iP is critical for maintenance of astrocytes and recovery from chronic autoimmunity, inhibition would likely greatly exacerbate patient symptoms if given during chronic stages of MS.

\section{Conclusions}

Our findings highlight the protective and stage-specific role of IFNY during chronic MS and EAE via upregulation of the iP in regional astrocytes. Due to a role in reducing ROS, degrading oxidatively damaged and poly-ubiquitinated proteins, IFNY-mediated upregulation of the iP represents a 
potential mechanism by which astrocytes protect the CNS during chronic neuroinflammation (Fig. 6). Further studies identifying an endogenous inhibitor of the iP in astrocytes [67] are needed to yield a potential therapeutic target for SPMS and PPMS patients.

\section{Supplementary information}

Supplementary information accompanies this paper at https://doi.org/10. 1186/s12974-020-01861-x.

Additional file 1: Figure S1. Confirmation of human astrocyte phenotype. Human brainstem and spinal cord astrocytes obtained from ScienCell Laboratories were plated in media alone until $80 \%$ confluent. RNA was then extracted and GRT-PCR was performed for the indicated transcripts.

Additional file 2: Figure S2. IFNy-regulated expression of the constitutive proteasome in regional human astrocytes. Human brainstem and spinal cord astrocytes were stimulated with $10 \mathrm{ng} / \mathrm{ml}$ IFNy for $0,6,12,24$ or $48 \mathrm{~h}$ and RNA was collected and analyzed for transcript levels of PSMB5, PSMB6, and PSMB7 by aRT-PCR, normalized to copies of GAPDH. Data represent the mean \pm SEM from 3 independent experiments. ${ }^{* *} P<$ $0.01,{ }^{* * *} P<0.001$ between regions by 2-way ANOVA.

Additional file 3: Figure S3. Regional inflammation and iP expression

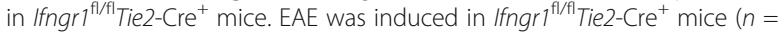
5) and (A) EAE clinical course was monitored. Following 30 days postimmunization, mice were perfused and the CNS was removed and cryopreserved for IHC analysis. White matter tracts of the brain stem and lumbar spinal cord were imaged using confocal microscopy at 20x magnification. (B) Tissue sections were labeled for MBP (red) and nuclei were counterstained with DAPI (blue). (D) Lesion area was quantified using ImageJ software. (C) Tissue sections were labeled for LMP2 (green), GFAP (red), and nuclei were counterstained with DAPI (blue). (F) Total LMP2 area and LMP2 colocalized with GFAP were analyzed. ${ }^{*} P<0.05$ between regions by 2-tailed Student's $t$ test.

Additional file 4: Figure S4. IFNGR1 deletion in astrocytes of Ifngr $7^{\mathrm{fl} / \mathrm{fl}} \mathrm{Gfap}-\mathrm{Cre}^{+}$mice. (A) IHC detection of astrocyte marker GFAP (red) or (B) Iba1 (red) and IFNGR1 (green) in the ventral spinal cords of Ifngr $1^{\mathrm{fl} / \mathrm{fl}}$

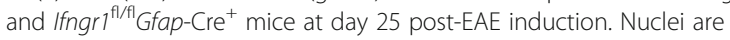
shown in blue. Images are representative of at least 4-20x images for each of 7 independent mice per genotype. Colocalization is quantified by Mean Mander's Coefficient using ImageJ software. Data points are representative of individual mice. ${ }^{* *} P<0.01$ between genotypes by 2 -tailed Student's $t$ test.

Additional file 5: Figure S5. LMP2 is not reduced in microglia/ monocytes in Ifngr $7^{\mathrm{fl} / \mathrm{fl}}$ Gfap-Cre ${ }^{+}$mice. IHC detection of Ibal (red) and LMP2 (green) in the ventral spinal cords of Ifngr $7^{f / / f l}$ and $/ f n g r 1^{f / / f l} G f a p-$ $\mathrm{Cre}^{+}$mice at day 25 post-EAE induction. Nuclei are shown in blue. Colocalization is quantified by Mander's coefficient using ImageJ software. Data points are representative of individual mice. Data represent the mean \pm SEM combined from 2 independent experiments and were analyzed by 2-tailed Student's $t$ test.

\section{Abbreviations}

IFN: Interferon; iP: Immunoproteasome; MS: Multiple sclerosis; MOG: Myelin oligodendrocyte glycoprotein; EAE: Experimental autoimmune encephalomyelitis; CNS: Central nervous system; RRMS: Relapsing-remitting MS; SPMS: Secondary progressive MS; PPMS: Primary progressive MS; IHC: Immunohistochemistry; ROS: Reactive oxygen species; PLP: Proteolipid protein; TBST: Tris-buffered saline, 0.1\% Tween ${ }^{\oplus} 20 ;$ PFA: Paraformaldehyde; WML: White matter lesions; NAWM: Normal-appearing white matter; IFNGR1: Interferon-gamma receptor; MBP: Myelin basic protein; IL: Interleukin

\section{Acknowledgements}

We thank Dr. Ranjan Dutta for the mRNA expression data, MS tissue, and insightful discussion and Dr. Melissa Varrecchia for technical and analytical assistance. We also thank Dr. Bruce Trapp for MS tissue collection, which is supported in part by NINDS R35 NS097303. This work was primarily supported by NIAID K22 Al125466 (JLW)

\section{Authors' contributions}

Conceptualization was done by BCS and JLW; designing research studies was done by BCS and JLW; BCS, MS, and JEJ were responsible for conducting experiments; $B C S, M S$, JEJ, and MWP were responsible for acquiring data; $B C S, M S$, and JLW were responsible for writing the manuscript; BCS, MS, MWP, and JLW were responsible for editing the manuscript; and supervision and funding acquisition was done by JLW. The authors read and approved the final manuscript.

\section{Funding}

We thank Dr. Bruce Trapp for MS tissue collection, which is supported in part by NINDS R35 NS097303. This work was primarily supported by NIAID K22 Al125466 (JLW).

\section{Availability of data and materials}

The datasets used and/or analyzed during the current study are available from the corresponding author on reasonable request.

\section{Ethics approval and consent to participate}

Unidentified postmortem brain specimens for microarray analysis were obtained from the UK Multiple Sclerosis Tissue Bank and the Human Brain and Spinal Fluid Resource Center at UCLA after obtaining approval of the Institutional Review Board at both institutions. All tissues used for IHC analysis were collected as part of the tissue procurement program approved by the Cleveland Clinic Institutional Review Board. Animals were housed in a specific pathogen-free barrier facility at the Cleveland Clinic Lerner Research Institute (Cleveland, $\mathrm{OH}, \mathrm{USA}$ ). All experiments were performed in compliance with and under the approval of the Cleveland Clinic Institutional Animal Care and Use Committee.

\section{Consent for publication}

Not applicable

\section{Competing interests}

The authors declare that they have no competing interests.

\section{Author details}

'Department of Neurosciences, Lerner Research Institute, Cleveland Clinic, Cleveland, OH, USA. ${ }^{2}$ Department of Biological, Geological, and Environmental Sciences, Cleveland State University, Cleveland, OH, USA. ${ }^{3}$ Brain Health Research Institute, Kent State University, Kent, OH, USA.

Received: 27 February 2020 Accepted: 29 May 2020

Published online: 12 June 2020

\section{References}

1. Berer K, Krishnamoorthy G. Microbial view of central nervous system autoimmunity. FEBS Lett. 2014;588:4207-13.

2. Trapp BD, Nave KA. Multiple sclerosis: an immune or neurodegenerative disorder? Annu Rev Neurosci. 2008;31:247-69.

3. Compston A, Coles A. Multiple sclerosis. Lancet. 2008;372:1502-17.

4. Hurwitz BJ. The diagnosis of multiple sclerosis and the clinical subtypes. Ann Indian Acad Neurol. 2009;12:226-30.

5. Thompson AJ, Kermode AG, Wicks D, MacManus DG, Kendall BE, Kingsley DP, McDonald WI. Major differences in the dynamics of primary and secondary progressive multiple sclerosis. Ann Neurol. 1991;29:53-62.

6. Confavreux C, Vukusic S, Moreau T, Adeleine P. Relapses and progression of disability in multiple sclerosis. N Engl J Med. 2000;343:1430-8.

7. Miller DH, Leary SM. Primary-progressive multiple sclerosis. Lancet Neurol. 2007:6:903-12.

8. Goodin DS, Frohman EM, Garmany GP Jr, Halper J, Likosky WH, Lublin FD, Silberberg DH, Stuart WH, van den Noort S, Therapeutics, et al. Disease modifying therapies in multiple sclerosis: report of the Therapeutics and Technology Assessment Subcommittee of the American Academy of Neurology and the MS Council for Clinical Practice Guidelines. Neurology. 2002;58:169-78.

9. Wingerchuk DM, Carter UL. Multiple sclerosis: current and emerging diseasemodifying therapies and treatment strategies. Mayo Clin Proc. 2014;89:225-40. 
10. Feinstein A, Freeman J, Lo AC. Treatment of progressive multiple sclerosis: what works, what does not, and what is needed. Lancet Neurol. 2015;14:194-207.

11. Leary $\mathrm{SM}$, Thompson AJ. Interferon beta-1a in primary progressive multiple sclerosis. J Neurol Sci. 2003;206:215-6.

12. van Oosten BW, Lai M, Hodgkinson S, Barkhof F, Miller DH, Moseley IF, Thompson AJ, Rudge P, McDougall A, McLeod JG, et al. Treatment of multiple sclerosis with the monoclonal anti-CD4 antibody CM-T412: results of a randomized, double-blind, placebo-controlled, MR-monitored phase II trial. Neurology. 1997;49:351-7.

13. TNF neutralization in MS. Results of a randomized, placebo-controlled multicenter study. Neurology. 1999;53:457.

14. Segal BM, Constantinescu CS, Raychaudhuri A, Kim L, Fidelus-Gort R, Kasper LH, Ustekinumab MSI. Repeated subcutaneous injections of IL12/23 p40 neutralising antibody, ustekinumab, in patients with relapsing-remitting multiple sclerosis: a phase II, double-blind, placebo-controlled, randomised, dose-ranging study. Lancet Neurol. 2008;7:796-804.

15. Brosnan CF, Raine CS. The astrocyte in multiple sclerosis revisited. Glia. 2013; 61:453-65.

16. Ponath $G$, Lincoln MR, Levine-Ritterman M, Park C, Dahlawi S, Mubarak M, Sumida T, Airas L, Zhang S, Isitan C, et al. Enhanced astrocyte responses are driven by a genetic risk allele associated with multiple sclerosis. Nat Commun. 2018:9:5337.

17. Patel JR, Williams JL, Muccigrosso MM, Liu L, Sun T, Rubin JB, Klein RS. Astrocyte TNFR2 is required for CXCL12-mediated regulation of oligodendrocyte progenitor proliferation and differentiation within the adult CNS. Acta Neuropathol. 2012;124:847-60.

18. John Lin CC, Yu K, Hatcher A, Huang TW, Lee HK, Carlson J, Weston MC, Chen F, Zhang Y, Zhu W, et al. Identification of diverse astrocyte populations and their malignant analogs. Nat Neurosci. 2017;20:396-405.

19. Zhang Y, Barres BA. Astrocyte heterogeneity: an underappreciated topic in neurobiology. Curr Opin Neurobiol. 2010;20:588-94.

20. Liddelow SA, Barres BA. Reactive astrocytes: production, function, and therapeutic potential. Immunity. 2017;46:957-67.

21. Bush TG, Puvanachandra N, Horner CH, Polito A, Ostenfeld T, Svendsen CN, Mucke L, Johnson MH, Sofroniew MV. Leukocyte infiltration, neuronal degeneration, and neurite outgrowth after ablation of scar-forming, reactive astrocytes in adult transgenic mice. Neuron. 1999;23:297-308.

22. Gao Q, Li Y, Chopp M. Bone marrow stromal cells increase astrocyte survival via upregulation of phosphoinositide 3-kinase/threonine protein kinase and mitogen-activated protein kinase kinase/extracellular signal-regulated kinase pathways and stimulate astrocyte trophic factor gene expression after anaerobic insult. Neuroscience. 2005;136:123-34.

23. Hayakawa K, Pham LD, Arai K, Lo EH. Reactive astrocytes promote adhesive interactions between brain endothelium and endothelial progenitor cells via HMGB1 and beta-2 integrin signaling. Stem Cell Res. 2014;12:531-8.

24. Anderson MA, Burda JE, Ren Y, Ao Y, O'Shea TM, Kawaguchi R, Coppola G, Khakh BS, Deming TJ, Sofroniew MV. Astrocyte scar formation aids central nervous system axon regeneration. Nature. 2016;532:195-200.

25. Arai K, Lo EH. Astrocytes protect oligodendrocyte precursor cells via MEK ERK and PI3K/Akt signaling. J Neurosci Res. 2010;88:758-63.

26. Sofroniew MV. Reactive astrocytes in neural repair and protection. Neuroscientist. 2005;11:400-7.

27. Voskuhl RR, Peterson RS, Song B, Ao Y, Morales LB, Tiwari-Woodruff S, Sofroniew MV. Reactive astrocytes form scar-like perivascular barriers to leukocytes during adaptive immune inflammation of the CNS. J Neurosci. 2009;29:11511-22.

28. Faulkner JR, Herrmann JE, Woo MJ, Tansey KE, Doan NB, Sofroniew MV. Reactive astrocytes protect tissue and preserve function after spinal cord injury. J Neurosci. 2004;24:2143-55.

29. Myer DJ, Gurkoff GG, Lee SM, Hovda DA, Sofroniew MV. Essential protective roles of reactive astrocytes in traumatic brain injury. Brain. 2006;129:2761-72

30. Olsson T. Cytokines in neuroinflammatory disease: role of myelin autoreactive T cell production of interferon-gamma. J Neuroimmunol. 1992;40:211-8.

31. Fletcher JM, Lalor SJ, Sweeney CM, Tubridy N, Mills KH. T cells in multiple sclerosis and experimental autoimmune encephalomyelitis. Clin Exp Immunol. 2010;162:1-11.

32. Kelchtermans $H$, Billiau A, Matthys P. How interferon-gamma keeps autoimmune diseases in check. Trends Immunol. 2008;29:479-86.

33. Arellano G, Ottum PA, Reyes LI, Burgos PI, Naves R. Stage-specific role of interferon-gamma in experimental autoimmune encephalomyelitis and multiple sclerosis. Front Immunol. 2015;6:492.
34. Ottum PA, Arellano G, Reyes LI, Iruretagoyena M, Naves R. Opposing roles of interferon-gamma on cells of the central nervous system in autoimmune neuroinflammation. Front Immunol. 2015;6:539.

35. Sosa RA, Murphey C, Robinson RR, Forsthuber TG. IFN-gamma ameliorates autoimmune encephalomyelitis by limiting myelin lipid peroxidation. Proc Natl Acad Sci U S A. 2015;112:E5038-47.

36. Sun L, Li Y, Jia X, Wang Q, Li Y, Hu M, Tian L, Yang J, Xing W, Zhang W, et al. Neuroprotection by IFN-gamma via astrocyte-secreted IL-6 in acute neuroinflammation. Oncotarget. 2017;8:40065-78.

37. Bever CT Jr, Panitch HS, Levy HB, McFarlin DE, Johnson KP. Gammainterferon induction in patients with chronic progressive MS. Neurology. 1991;41:1124-7.

38. Furlan R, Brambilla E, Ruffini F, Poliani PL, Bergami A, Marconi PC, Franciotta DM, Penna G, Comi G, Adorini L, Martino G. Intrathecal delivery of IFNgamma protects C57BL/6 mice from chronic-progressive experimental autoimmune encephalomyelitis by increasing apoptosis of central nervous system-infiltrating lymphocytes. J Immunol. 2001;167:1821-9.

39. Miller NM, Wang J, Tan Y, Dittel BN. Anti-inflammatory mechanisms of IFNgamma studied in experimental autoimmune encephalomyelitis reveal neutrophils as a potential target in multiple sclerosis. Front Neurosci. 2015;9:287.

40. Voorthuis JA, Uitdehaag BM, De Groot CJ, Goede PH, van der Meide PH, Dijkstra CD. Suppression of experimental allergic encephalomyelitis by intraventricular administration of interferon-gamma in Lewis rats. Clin Exp Immunol. 1990;81:183-8.

41. Billiau A, Heremans $H$, Vandekerckhove F, Dijkmans R, Sobis H, Meulepas E, Carton $\mathrm{H}$. Enhancement of experimental allergic encephalomyelitis in mice by antibodies against IFN-gamma. J Immunol. 1988;140:1506-10.

42. Jagessar SA, Gran B, Heijmans N, Bauer J, Laman JD, t Hart BA, Constantinescu CS. Discrepant effects of human interferon-gamma on clinical and immunological disease parameters in a novel marmoset model for multiple sclerosis. J Neurolmmune Pharmacol. 2012;7:253-65.

43. Heremans H, Dillen C, Groenen M, Martens E, Billiau A. Chronic relapsing experimental autoimmune encephalomyelitis (CREAE) in mice: enhancement by monoclonal antibodies against interferon-gamma. Eur J Immunol. 1996;26:2393-8.

44. Lees JR, Golumbek PT, Sim J, Dorsey D, Russell JH. Regional CNS responses to IFN-gamma determine lesion localization patterns during EAE pathogenesis. J Exp Med. 2008;205:2633-42.

45. Stromnes IM, Cerretti LM, Liggitt D, Harris RA, Goverman JM. Differential regulation of central nervous system autoimmunity by $T(H) 1$ and $T(H) 17$ cells. Nat Med. 2008;14:337-42.

46. Simmons SB, Liggitt D, Goverman JM. Cytokine-regulated neutrophil recruitment is required for brain but not spinal cord inflammation during experimental autoimmune encephalomyelitis. J Immunol. 2014;193:555-63.

47. Krakowski M, Owens T. Interferon-gamma confers resistance to experimental allergic encephalomyelitis. Eur J Immunol. 1996;26:1641-6.

48. Ferber IA, Brocke S, Taylor-Edwards C, Ridgway W, Dinisco C, Steinman L, Dalton D, Fathman CG. Mice with a disrupted IFN-gamma gene are susceptible to the induction of experimental autoimmune encephalomyelitis (EAE). J Immunol. 1996;156:5-7.

49. Sabatino JJ Jr, Shires J, Altman JD, Ford ML, Evavold BD. Loss of IFN-gamma enables the expansion of autoreactive $\mathrm{CD}^{+} \mathrm{T}$ cells to induce experimental autoimmune encephalomyelitis by a nonencephalitogenic myelin variant antigen. J Immunol. 2008;180:4451-7.

50. Willenborg DO, Fordham S, Bernard CC, Cowden WB, Ramshaw IA. IFNgamma plays a critical down-regulatory role in the induction and effector phase of myelin oligodendrocyte glycoprotein-induced autoimmune encephalomyelitis. J Immunol. 1996;157:3223-7.

51. Naves R, Singh SP, Cashman KS, Rowse AL, Axtell RC, Steinman L, Mountz JD, Steele C, De Sarno P, Raman C. The interdependent, overlapping, and differential roles of type I and II IFNs in the pathogenesis of experimental autoimmune encephalomyelitis. J Immunol. 2013;191:2967-77.

52. Pierson ER, Goverman JM. GM-CSF is not essential for experimental autoimmune encephalomyelitis but promotes brain-targeted disease. JCl Insight. 2017;2:e92362.

53. Hindinger C, Bergmann CC, Hinton DR, Phares TW, Parra Gl, Hussain S, Savarin C, Atkinson RD, Stohlman SA. IFN-gamma signaling to astrocytes protects from autoimmune mediated neurological disability. PLoS One. 2012; $7:$ :42088.

54. Savarin C, Hinton DR, Valentin-Torres A, Chen Z, Trapp BD, Bergmann CC, StohIman SA. Astrocyte response to IFN-gamma limits IL-6-mediated 
microglia activation and progressive autoimmune encephalomyelitis. $J$ Neuroinflammation. 2015;12:79.

55. Lycklama G, Thompson A, Filippi M, Miller D, Polman C, Fazekas F, Barkhof F. Spinal-cord MRI in multiple sclerosis. Lancet Neurol. 2003;2:555-62.

56. Nijeholt GJ, van Walderveen MA, Castelijns JA, van Waesberghe JH, Polman C, Scheltens P, Rosier PF, Jongen PJ, Barkhof F. Brain and spinal cord abnormalities in multiple sclerosis. Correlation between MRI parameters, clinical subtypes and symptoms. Brain. 1998;121(Pt 4):687-97.

57. Brownlee WJ, Altmann DR, Alves Da Mota P, Swanton JK, Miszkiel KA, Wheeler-Kingshott CG, Ciccarelli O, Miller DH. Association of asymptomatic spinal cord lesions and atrophy with disability 5 years after a clinically isolated syndrome. Mult Scler. 2017;23:665-74.

58. Kearney H, Schneider T, Yiannakas MC, Altmann DR, Wheeler-Kingshott CA, Ciccarelli O, Miller DH. Spinal cord grey matter abnormalities are associated with secondary progression and physical disability in multiple sclerosis. Neurol Neurosurg Psychiatry. 2015;86:608-14.

59. Kearney H, Rocca MA, Valsasina P, Balk L, Sastre-Garriga J, Reinhardt J, Ruggieri S, Rovira A, Stippich C, Kappos L, et al. Magnetic resonance imaging correlates of physical disability in relapse onset multiple sclerosis of long disease duration. Mult Scler. 2014;20:72-80.

60. Goodin DS. Magnetic resonance imaging as a surrogate outcome measure of disability in multiple sclerosis: Have we been overly harsh in our assessment? Ann Neurol. 2006;59:597-605.

61. Chomyk AM, Volsko C, Tripathi A, Deckard SA, Trapp BD, Fox RJ, Dutta R. DNA methylation in demyelinated multiple sclerosis hippocampus. Sci Rep. 2017;7:8696.

62. Huynh JL, Garg P, Thin TH, Yoo S, Dutta R, Trapp BD, Haroutunian V, Zhu J, Donovan MJ, Sharp AJ, Casaccia P. Epigenome-wide differences in pathology-free regions of multiple sclerosis-affected brains. Nat Neurosci. 2014:17:121-30

63. Dutta R, Chang A, Doud MK, Kidd GJ, Ribaudo MV, Young EA, Fox RJ, Staugaitis SM, Trapp BD. Demyelination causes synaptic alterations in hippocampi from multiple sclerosis patients. Ann Neurol. 2011;69:445-54.

64. Dutta R, Chomyk AM, Chang A, Ribaudo MV, Deckard SA, Doud MK, Edberg DD, Bai B, Li M, Baranzini SE, et al. Hippocampal demyelination and memory dysfunction are associated with increased levels of the neuronal microRNA miR-124 and reduced AMPA receptors. Ann Neurol. 2013;73:637-45.

65. Williams JL, Patel JR, Daniels BP, Klein RS. Targeting CXCR7/ACKR3 as a therapeutic strategy to promote remyelination in the adult central nervous system. J Exp Med. 2014;211:791-9.

66. Daniels BP, Jujjavarapu H, Durrant DM, Williams JL, Green RR, White JP, Lazear HM, Gale M, Jr., Diamond MS, Klein RS: Regional astrocyte IFN signaling restricts pathogenesis during neurotropic viral infection. J Clin Invest 2017

67. Anderson AM, Kalimutho M, Harten S, Nanayakkara DM, Khanna KK, Ragan MA. The metastasis suppressor RARRES3 as an endogenous inhibitor of the immunoproteasome expression in breast cancer cells. Sci Rep. 2017;7:39873.

68. Seifert U, Bialy LP, Ebstein F, Bech-Otschir D, Voigt A, Schroter F, Prozorovski T, Lange N, Steffen J, Rieger M, et al. Immunoproteasomes preserve protein homeostasis upon interferon-induced oxidative stress. Cell. 2010;142:613-24.

69. Pickering A, Miller R: Immunoproteasome system in aging, lifespan, and age-associated disease. In; 2017.

70. Orre M, Kamphuis W, Dooves S, Kooijman L, Chan ET, Kirk CJ, Dimayuga Smith V, Koot S, Mamber C, Jansen AH, et al. Reactive glia show increased immunoproteasome activity in Alzheimer's disease. Brain. 2013;136:1415-31.

71. Limanaqi F, Biagioni F, Gaglione A, Busceti CL, Fornai F. A sentinel in the crosstalk between the nervous and immune system: the (immuno)proteasome. Front Immunol. 2019;10.

72. Pekny M, Pekna M, Messing A, Steinhauser C, Lee JM, Parpura V, Hol EM, Sofroniew MV, Verkhratsky A. Astrocytes: a central element in neurological diseases. Acta Neuropathol. 2016;131:323-45.

73. Mishto M, Bellavista E, Ligorio C, Textoris-Taube K, Santoro A, Giordano M, D'Alfonso S, Listi F, Nacmias B, Cellini E, et al. Immunoproteasome LMP2 $60 \mathrm{HH}$ variant alters MBP epitope generation and reduces the risk to develop multiple sclerosis in Italian female population. PLoS One. 2010;5: e9287.

74. Colombo E, Farina C. Astrocytes: key regulators of neuroinflammation. Trends Immunol. 2016;37:608-20.

75. Bjartmar C, Kidd G, Mörk S, Rudick R, Trapp BD. Neurological disability correlates with spinal cord axonal loss and reduced $\mathrm{N}$-acetyl aspartate in chronic multiple sclerosis patients. Ann Neurol. 2000;48:893-901.
76. Scotti G, Scialfa G, Biondi A, Landoni L, Caputo D, Cazzullo CL. Magnetic resonance in multiple sclerosis. Neuroradiology. 1986;28:319-23.

77. Ransohoff RM. Animal models of multiple sclerosis: the good, the bad and the bottom line. Nat Neurosci. 2012:15:1074-7.

78. Verkhratsky A, Nedergaard M. Physiology of astroglia. Physiol Rev. 2018;98: 239-389.

79. Cunningham C, Dunne A, Lopez-Rodriguez AB. Astrocytes: heterogeneous and dynamic phenotypes in neurodegeneration and innate immunity. Neuroscientist. 2018;25:455-74.

80. Panitch HS. Interferons in multiple sclerosis. Drugs. 1992;44:946-62.

81. Renno T, Taupin V, Bourbonnière L, Verge G, Tran E, De Simone R, Krakowski M, Rodriguez M, Peterson A, Owens T. Interferon- $\gamma$ in progression to chronic demyelination and neurological deficit following acute EAE. Mol Cell Neurosci. 1998;12:376-89.

82. Payne S, Val SD, Neal A. Endothelial-specific Cre mouse models. Arterioscler Thromb Vasc Biol. 2018;38:2550-61.

83. Wilson SJ, Lowe KL, Bokoch MP, Srinivasan Y, Wu RS, Coughlin SR. Abstract 437: endothelial cell gene expression in hypertensive mice. Arterioscler Thromb Vasc Biol. 2017;37:A437.

84. Bö L, Mörk S, Kong PA, Nyland H, Pardo CA, Trapp BD. Detection of MHC class II-antigens on macrophages and microglia, but not on astrocytes and endothelia in active multiple sclerosis lesions. J Neuroimmunol. 1994;51: 135-46.

85. Matsumoto Y, Ohmori K, Fujiwara M. Immune regulation by brain cells in the central nervous system: microglia but not astrocytes present myelin basic protein to encephalitogenic T cells under in vivo-mimicking conditions. Immunology. 1992;76:209-16.

86. Kort JJ, Kawamura K, Fugger L, Weissert R, Forsthuber TG. Efficient presentation of myelin oligodendrocyte glycoprotein peptides but not protein by astrocytes from HLA-DR2 and HLA-DR4 transgenic mice. J Neuroimmunol. 2006;173:23-34.

87. Ebstein F, Kloetzel P-M, Krüger E, Seifert U. Emerging roles of immunoproteasomes beyond MHC class I antigen processing. Cell Mol Life Sci. 2012;69:2543-58.

88. von Brzezinski L, Saring P, Landgraf P, Cammann C, Seifert U, Dieterich DC. Low neurotoxicity of ONX-0914 supports the idea of specific immunoproteasome inhibition as a side-effect-limiting, therapeutic strategy. Eur J Microbiol Immunol (Bp). 2017;7:234-45.

89. Zilberberg J, Matos J, Dziopa E, Dziopa L, Yang Z, Kirk CJ, Assefnia S, Korngold R. Inhibition of the immunoproteasome subunit LMP7 with ONX 0914 ameliorates graft-versus-host disease in an MHC-matched minor histocompatibility antigen-disparate murine model. Biology of Blood and Marrow Transplantation. 2015;21:1555-64.

90. Althof N, Goetzke CC, Kespohl M, Voss K, Heuser A, Pinkert S, Kaya Z, Klingel K, Beling A. The immunoproteasome-specific inhibitor ONX 0914 reverses susceptibility to acute viral myocarditis. EMBO Molecular Medicine. 2018;10:200-18.

91. Basler M, Mundt S, Muchamuel T, Moll C, Jiang J, Groettrup M, Kirk CJ. Inhibition of the immunoproteasome ameliorates experimental autoimmune encephalomyelitis. EMBO Molecular Medicine. 2014;6:226-38.

92. Williams JL, Manivasagam S, Smith BC, Sim J, Vollmer LL, Daniels BP, Russell $\mathrm{JH}$, Klein RS: Astrocyte-T cell crosstalk regulates region-specific neuroinflammation. Glia 2020.

93. Jha MK, Jo M, Kim JH, Suk K. Microglia-astrocyte crosstalk: an intimate molecular conversation. Neuroscientist. 2019;25:227-40.

94. Liu R-T, Zhang P, Yang C-L, Pang Y, Zhang M, Zhang N, Yue L-T, Li X-L, Li H, Duan R-S. ONX-0914, a selective inhibitor of immunoproteasome, ameliorates experimental autoimmune myasthenia gravis by modulating humoral response. J Neuroimmunol. 2017;311:71-8.

95. Kirby L, Jin J, Cardona JG, Smith MD, Martin KA, Wang J, Strasburger $H_{\text {, }}$ Herbst L, Alexis M, Karnell J, et al. Oligodendrocyte precursor cells present antigen and are cytotoxic targets in inflammatory demyelination. Nat Commun. 2019:10:3887.

96. Grimm S, Ott C, Horlacher M, Weber D, Hohn A, Grune T. Advancedglycation-end-product-induced formation of immunoproteasomes: involvement of RAGE and Jak2/STAT1. Biochem J. 2012;448:127-39.

97. Campello L, Esteve-Rudd J, Cuenca N, Martin-Nieto J. The ubiquitinproteasome system in retinal health and disease. Mol Neurobiol. 2013;47: 790-810.

98. Hussong SA, Kapphahn RJ, Phillips SL, Maldonado M, Ferrington DA. Immunoproteasome deficiency alters retinal proteasome's response to stress. J Neurochem. 2010;113:1481-90. 
99. Forrester SJ, Kikuchi DS, Hernandes MS, Xu Q, Griendling KK. Reactive oxygen species in metabolic and inflammatory signaling. Circ Res. 2018;122: 877-902.

100. van Deventer $S$, Neefjes J. The immunoproteasome cleans up after inflammation. Cell. 2010;142:517-8.

101. Zheng J, Bizzozero OA. Reduced proteasomal activity contributes to the accumulation of carbonylated proteins in chronic experimental autoimmune encephalomyelitis. J Neurochem. 2010;115:1556-67.

102. Smerjac SM, Bizzozero OA. Cytoskeletal protein carbonylation and degradation in experimental autoimmune encephalomyelitis. J Neurochem. 2008;105:763-72.

103. van Horssen J, Schreibelt G, Drexhage J, Hazes T, Dijkstra CD, van der Valk $P$, de Vries HE. Severe oxidative damage in multiple sclerosis lesions coincides with enhanced antioxidant enzyme expression. Free Radic Biol Med. 2008; 45:1729-37.

104. Bizzozero OA, DeJesus G, Callahan K, Pastuszyn A. Elevated protein carbonylation in the brain white matter and gray matter of patients with multiple sclerosis. J Neurosci Res. 2005;81:687-95.

105. Wheeler MA, Clark IC, Tjon EC, Li Z, Zandee SEJ, Couturier CP, Watson BR, Scalisi G, Alkwai S, Rothhammer V, et al. MAFG-driven astrocytes promote CNS inflammation. Nature. 2020;578:593-9.

106. Rothhammer V, Quintana FJ. Control of autoimmune CNS inflammation by astrocytes. Semin Immunopathol. 2015;37:625-38.

107. Rothhammer V, Quintana FJ. The aryl hydrocarbon receptor: an environmental sensor integrating immune responses in health and disease. Nat Rev Immunol. 2019:19:184-97.

108. Zheng J, Bizzozero OA. Decreased activity of the $20 \mathrm{~S}$ proteasome in the brain white matter and gray matter of patients with multiple sclerosis. J Neurochem. 2011;117:143-53.

109. Ding Q, Martin S, Dimayuga E, Bruce-Keller AJ, Keller JN. LMP2 knock-out mice have reduced proteasome activities and increased levels of oxidatively damaged proteins. Antioxid Redox Signal. 2006;8:130-5.

110. White RE, McTigue DM, Jakeman LB. Regional heterogeneity in astrocyte responses following contusive spinal cord injury in mice. J Comp Neurol. 2010:518:1370-90

111. Matias I, Morgado J, Gomes FCA. Astrocyte heterogeneity: impact to brain aging and disease. Front Aging Neurosci. 2019:11:59.

112. Tassoni A, Farkhondeh V, Itoh Y, Itoh N, Sofroniew MV, Voskuhl RR. The astrocyte transcriptome in EAE optic neuritis shows complement activation and reveals a sex difference in astrocytic C3 expression. Sci Rep. 2019;9: 10010.

113. Itoh N, Itoh Y, Tassoni A, Ren E, Kaito M, Ohno A, Ao Y, Farkhondeh V, Johnsonbaugh $\mathrm{H}$, Burda J, et al. Cell-specific and region-specific transcriptomics in the multiple sclerosis model: focus on astrocytes. Proc Natl Acad Sci. 2018;115:E302

114. Basler M, Mundt S, Bitzer A, Schmidt C, Groettrup M. The immunoproteasome: a novel drug target for autoimmune diseases. Clin Exp Rheumatol. 2015;33:574-9.

\section{Publisher's Note}

Springer Nature remains neutral with regard to jurisdictional claims in published maps and institutional affiliations.

Ready to submit your research? Choose BMC and benefit from:
- fast, convenient online submission
- thorough peer review by experienced researchers in your field
- rapid publication on acceptance
- support for research data, including large and complex data types
- gold Open Access which fosters wider collaboration and increased citations
- maximum visibility for your research: over 100M website views per year
At BMC, research is always in progress.
Learn more biomedcentral.com/submissions

